\title{
Adorning Materials in Middles
}

Yoon-kyoung $\mathrm{Joh}^{\dagger}$

Mokpo National University

\begin{abstract}
This paper claims that adorning materials in middles can commonly be translated into adverbials since modality, negation, and focus can all be expressed using various types of adverbials. Through the analytical lens that views middle constructions as distributivity constructions that are essentially reduced to plurality, this common property among adorning materials in middles is highly interesting. Thus, this paper accounts for the adorning materials in middles in Joh's (2016) analysis, which treats adverbials in middles as one of distributivity's core arguments. This paper also discusses how adverbials that are implicitly inserted in middle sentences can be conditioned. To answer this question, this paper relies on the differentiating effect that Sohn (2003) examined, extending the previously proposed unexpectedness condition.
\end{abstract}

Keywords: middle, adverbial, focus, modal, negation

\section{Introduction}

Citing Roberts (1987), Chung (2001) discusses a problem related to the adorning materials in middles. The typical middle construction is illustrated by the examples in (1). However, the adorning materials in (2) such as a modal verb, negation and focus enable the construction to survive even though the sentences in (2) are not the typical cases of middle constructions. Chung (2001) could not detect the common property of the adorning materials illustrated in (2) and leaves it as a further research question. This paper would like to tackle this very issue.

(1) a. The vase breaks easily.

b. The book sells easily.

(2) a. The hand-made clothes could sell.

b. This paper doesn't cut.

c. This dress BUTTONS.

\footnotetext{
† Corresponding author: ykjoh@mokpo.ac.kr
} 
The common property that this paper finds regarding the adorning materials in the middle construction is that they all can be transformed into adverbials as illustrated below. The modal verb could can be translated into a modal adverb probably. The negative particle not can be translated into a negative adverb never. Finally, the phonetic focus placed on the predicate button can be translated into a focusing adverb particularly.

(3) a. The hand-made clothes probably sell.

b. This paper never cuts.

c. This dress particularly buttons.

Then, the question is why the common property that they can be translated into a type of adverbial makes the construction survive. To answer this question, we will depend on Joh (2016) which analyzes middle constructions as distributivity constructions, where the adverbial functions as one of the core arguments.

This paper is organized as follows. First, section 2 will introduce Joh (2016). Then, in section 3 , we will discuss the adverbial properties of the adorning materials in middles shown in (2). Then, section 4 will provide the analyses for the middle constructions with the adorning materials. Section 5 will discuss the characteristic effect of the adverbials transformed from the adorning materials in middles and the adverbials which are implicitly inserted in general.

\section{Middles as Distributivity Constructions}

This section will introduce Joh (2016). The first subsection will focus on her claim that middle constructions are distributivity constructions. Then, the second sub-section will discuss how she handles diverse cases of middles under such a claim. The final subsection will show how she analyzes three classes of middles formal-semantically one by one.

\subsection{Distributivity}

First, Joh (2016) claims that middle constructions are distributivity constructions. Previously, Lee (2001) puts forth a recursiveness condition for middle constructions in the sense that middle constructions involve repeated regular actions denoted by 
the predicate with respect to the subject. Krifka et. al. (1995) argued for the genericity condition of middle constructions since they generally make generic statements, not statements about a particular object or instance. The common property of these previous observations is that they all see that middle constructions are engaged with plurality. Thus, in terms of the fact that plurality is essentially the property of distributivity as Landman (2000) finds, Joh (2016) argues that middle constructions state about how each (token) of the subject involves in a certain action with respect to a certain adverbial property, allowing for the possibility that the universal force can be contextually adjusted.

Choe (1987) claims that distributivity meaning is derived simply when certain conditions are met. When there are a plural subject called a Sorting Key (henceforth, SrtKy), an indefinite Distributed Share (henceforth, DstrShr), and a certain Relation that connects the SrtKy and the DstrShr, distributivity automatically arises. In terms of this view, Joh (2016) claims that the subject of the middle constructions serves as the SrtKy and the predicate serves as a Relation and the adverbial in middle constructions functions as the DstrShr, providing explanations about some dubious cases.

In essence, Joh (2016) encompasses the intuitions of Lee (2001) and Krifka et. al. (1995) such as recursiveness and genericity in the sense that what they basically argued for are types of plurality for middle constructions and Joh (2016) employs a pluralization operator to encode the semantics of middle constructions. Yet, when it comes to pinning down exactly what kinds of plurality, Joh (2016) adopts the theory of Choe (1987) who provides more clear conditions for generating distributivity since arguments of middle sentences can basically meet the conditions that Choe (1987) proposes. The reason why Joh (2016) sticks to the idea that distributivity of middle sentences is reduced to plurality by projecting distributivity of middle sentences from a pluralization operator is also due to Landman's (2000) claim that distributivity is reduced to plurality.

By claiming that middle constructions are distributivity constructions, Joh (2016) introduces the universal quantificational force to the middle constructions. Yet, by employing a cover variable that allows for non-maximality, she still captures the intuitions based on other kinds of plurality that can be contextually allowed in addition to distributivity. In other words, recursiveness, genericity, and distributivity are all related to one another since they all are types of plurality. 


\subsection{Three classes of middles}

Yet, diverse examples of middle constructions do not make the claim simply implemented. Thus, Joh (2016) classifies middle constructions into three classes. Group 1 is the default case of distributivity since there is a plural subject, relation and an indefinite adverbial, as shown in (4). Yet, not all the middle constructions are realized as this class.

(4) Group 1: Middles with a Plural Subject

a. Little children amuse easily.

b. Cheap basketballs dribble poorly.

Thus, she discusses Group 2 and Group 3. In Group 2, there is a relation and an adverbial but apparently the plural subject is missing. Instead, there is a singular subject. However, Joh (2016) claims that we can extract plural tokens out of the singular subject since the middles belonging to Group 2 do not talk about a particular singular subject but talk about all the tokens of the subject in general.

(5) Group 2: Middles with a Singular Subject
a. This metal anneals easily.
b. Dark paint covers poorly.
c. This coat buttons easily.
d. This cup does crush easily.

Finally, in Group 3, an indefinite adverbial can be missing. Here, the subject can be either plural or singular. If the subject is plural, it is the default setting. However, if the subject is singular, the token-extraction operation can take place. Also, the missing adverbial can be implicitly present when a certain condition is satisfied.

(6) Group 3: Middles without an Adverb
a. Riches tend to accumulate.
b. This pen scratches.

To be more specific, to deal with the missing DstrShr which is one of the core arguments in distributivity, she postulates an implicit adverbial. Previously, Cho (2002) claimed that middle constructions are possible when the unexpectedness sense is available. Based on this claim, Joh (2016) claims that the middle construction 
is possible even when the adverbial is not overtly present if the default adverbial really which conveys the unexpectedness sense can serve as an implicit argument.

Thus, (7a) is a possible middle construction since the adverbial really can be inserted. However, (7b) is an illicit middle construction because it is awkward to insert the adverbial really since it is largely expected that all the books are read.

(7) a. Bureaucrats BRIBE.

b. *This book reads.

2.3. Analyses for the three classes of middles

To provide a formal semantic analysis, Joh (2016) depends on the pluralization operator1) defined in (8) and Bittner's (1994) lambda-abstraction rule in (9). Landman (2000) claims that distributivity is essentially the property of plurality and Zimmermann (200) encodes $\forall \exists$-structure for distributivity. Based on these claims, Joh (2016) argues that the pluralization operator can basically evoke the distributivity of the middle sentences. Also, the order of the arguments does not have to be fixed when it comes to the middle construction since a more liberated version of the lambda-abstraction rule in (9) can be employed.

(8) $\left[\left[{ }^{*} \mathrm{ij}\right]\right]=\lambda \mathrm{P}_{<\alpha, t>}, \forall \mathrm{z}\left[\mathrm{z}_{<\alpha>} \in \mathrm{Z}_{\mathrm{i}<\alpha, t>\operatorname{Cov}} \rightarrow \exists \mathrm{x}_{<\alpha>}[\mathrm{P}(\mathrm{x})\right.$ $\left.\left.\& \mathrm{R}_{\mathrm{j}<\mathrm{e},<\alpha, \mathrm{t}>>}(\mathrm{x})(\mathrm{z})\right]\right]$

(9) Let $\alpha$ have a translation $[[\alpha]]$ and let the index 'i' be the index of either $\alpha$ or a sister of $\alpha$, and let $[[\alpha]]$ contain a variable $\mathrm{u}$ with index 'i.' Then $\lambda \mathrm{u}_{\mathrm{i} .}[[\alpha]]$ is a translation of $\alpha$.

Now, let us introduce how Joh (2016) analyzes each group of middle sentences. The sentence in (10) belongs to Group 1 which is the default case where there are three core arguments of distributivity. The plural subject little children is the SrtKy and the indefinite adverbial easily is the DstrShr and the main verb amuse is the Relation.

(10) Little children amuse easily.

1) The semantic type $\alpha$ is for both the entity type and the event type. 
(11)

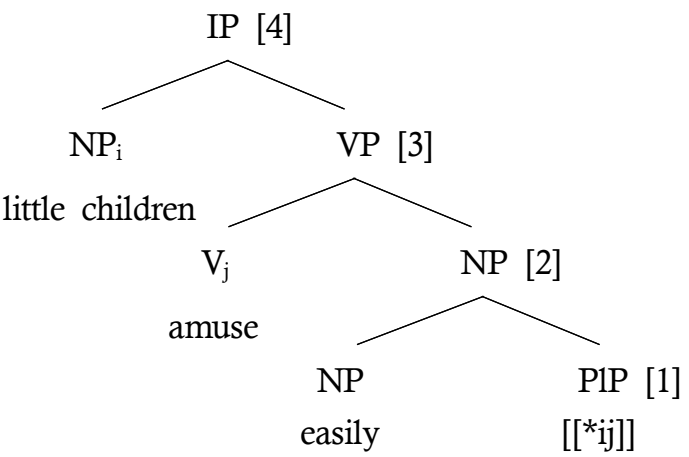

$$
\begin{aligned}
& {[[1]]=\lambda P \cdot \forall z\left[z \in Z_{i \text { Cov }} \rightarrow \exists x\left[P(x) \& R_{\mathrm{j}}(\mathrm{x})(\mathrm{z})\right]\right]} \\
& {[[2]]=\forall \mathrm{z}\left[\mathrm{z} \in \mathrm{Z}_{\mathrm{i} \text { Cov }} \rightarrow \exists \mathrm{x}\left[\text { easily }(\mathrm{x}) \& \mathrm{R}_{\mathrm{j}}(\mathrm{x})(\mathrm{z})\right]\right]} \\
& {[[2]]=\lambda \mathrm{R}_{\mathrm{j} .} \cdot \forall \mathrm{z}\left[\mathrm{z} \in \mathrm{Z}_{\mathrm{iCov}} \rightarrow \exists \mathrm{x}\left[\text { easily }(\mathrm{x}) \& \mathrm{R}_{\mathrm{j}}(\mathrm{x})(\mathrm{z})\right]\right]} \\
& {[[3]]=\forall \mathrm{z}\left[\mathrm{z} \in \mathrm{Z}_{\mathrm{iCov}} \rightarrow \exists \mathrm{x}[\text { easily }(\mathrm{x}) \& \text { amuse }(\mathrm{z}, \mathrm{x})]\right]} \\
& {[[3]]=\lambda \mathrm{Z}_{\mathrm{i}} \cdot \forall \mathrm{z}\left[\mathrm{z} \in \mathrm{Z}_{\mathrm{iCov}} \rightarrow \exists \mathrm{x}[\text { easily }(\mathrm{x}) \& \text { amuse }(\mathrm{z}, \mathrm{x})]\right]} \\
& {[[4]]=\forall \mathrm{z}\left[\mathrm{z} \in[[\text { little children }]]_{\text {Cov }} \rightarrow \exists \mathrm{x}[\text { easily }(\mathrm{x}) \& \text { amuse }(\mathrm{z}, \mathrm{x})]\right]}
\end{aligned}
$$

The middle sentence in (12) belongs to Group 2 where there is apparently the singular subject instead of the plural subject. However, Joh (2016) claims that we can extract plural tokens out of the singular subject since the sentence does not talk about one instance of the metal annealing easily but it has essentially the plural sense which can be projected as the distributive sense that each token of the metal anneals easily. Thus, the difference from the analysis above is that there is the token-abstraction operation for the SrtKy.

(12) This metal anneals easily. 
(13)

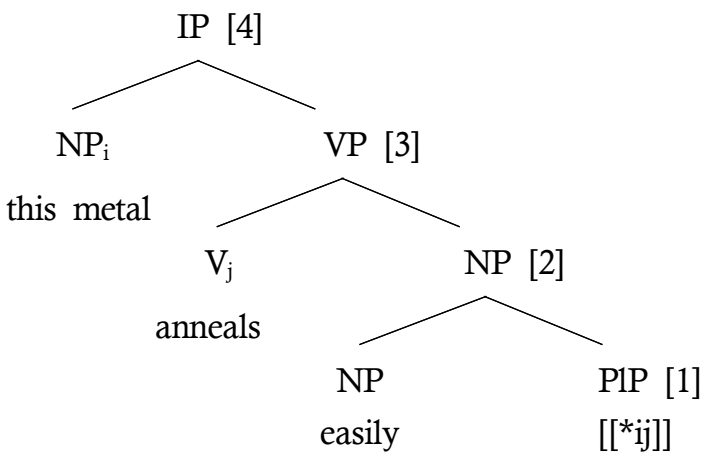

$[[1]]=\lambda \mathrm{P} \cdot \forall z\left[z \in Z_{\text {iCov }} \rightarrow \exists x\left[\mathrm{P}(\mathrm{x}) \& \mathrm{R}_{\mathrm{j}}(\mathrm{x})(\mathrm{z})\right]\right]$

$[[2]]=\forall z\left[z \in Z_{\text {iCov }} \rightarrow \exists x\left[\right.\right.$ easily $\left.\left.(x) \& R_{\mathrm{j}}(\mathrm{x})(\mathrm{z})\right]\right]$

$[[2]]=\lambda \mathrm{R}_{\mathrm{j}} \cdot \forall \mathrm{z}\left[\mathrm{z} \in \mathrm{Z}_{\mathrm{iCov}} \rightarrow \exists \mathrm{x}\left[\operatorname{easily}(\mathrm{x}) \& \mathrm{R}_{\mathrm{j}}(\mathrm{x})(\mathrm{z})\right]\right]$

$[[3]]=\forall z\left[z \in Z_{\text {iCov }} \rightarrow \exists x[\operatorname{easily~(x)~\& ~anneals~}(\mathrm{z}, \mathrm{x})]\right]$

$[[3]]=\lambda Z_{i} \cdot \forall z\left[z \in Z_{\text {iCov }} \rightarrow \exists x[\right.$ easily $(x) \&$ anneals $\left.(\mathrm{z}, \mathrm{x})]\right]$

$[[4]]=\forall z\left[z \in\right.$ token $\left[[\text { this metal] }]_{\mathrm{Cov}} \rightarrow \exists x[\right.$ easily $(\mathrm{x}) \&$ anneals $\left.(\mathrm{z}, \mathrm{x})]\right]$

The last group is characterized with a missing DstrShr. However, Joh (2016) claims that there is an implicit DstrShr which conveys the sense of unexpectedness which makes the middle construction possible without the apparent adverbial present. Thus, the sentence in (14) without the overt adverbial can be analysed in a uniform way as the sentences above since the adverbial really which delivers the meaning of unexpectedness can be implicitly inserted.

(14) This pen scratches (really).

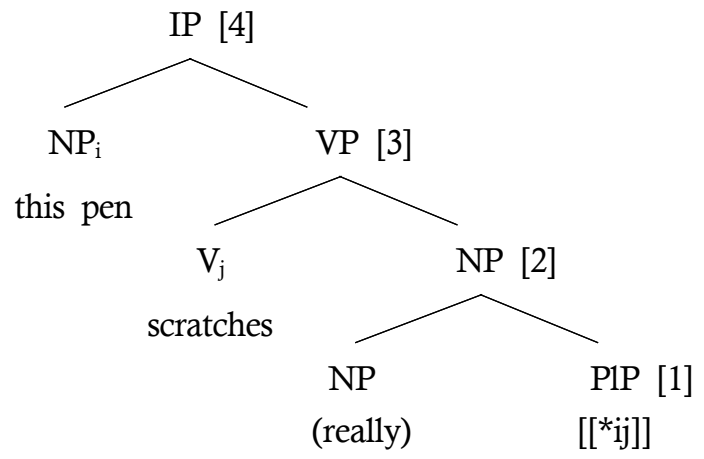




$$
\begin{aligned}
& {[[1]]=\lambda \mathrm{P} \cdot \forall \mathrm{z}\left[\mathrm{z} \in \mathrm{Z}_{\mathrm{iCov}} \rightarrow \exists \mathrm{x}\left[\mathrm{P}(\mathrm{x}) \& \mathrm{R}_{\mathrm{j}}(\mathrm{x})(\mathrm{z})\right]\right]} \\
& {[[2]]=\forall \mathrm{z}\left[\mathrm{z} \in \mathrm{Z}_{\mathrm{iCov}} \rightarrow \exists \mathrm{x}\left[\text { really }(\mathrm{x}) \& \mathrm{R}_{\mathrm{j}}(\mathrm{x})(\mathrm{z})\right]\right]} \\
& {[[2]]=\lambda \mathrm{R}_{\mathrm{j}} \cdot \forall \mathrm{z}\left[\mathrm{z} \in \mathrm{Z}_{\mathrm{iCov}} \rightarrow \exists \mathrm{x}\left[\text { really }(\mathrm{x}) \& \mathrm{R}_{\mathrm{j}}(\mathrm{x})(\mathrm{z})\right]\right]} \\
& {[[3]]=\forall \mathrm{z}\left[\mathrm{z} \in \mathrm{Z}_{\mathrm{iCov}} \rightarrow \exists \mathrm{x}[\text { really }(\mathrm{x}) \& \text { scratches }(\mathrm{z}, \mathrm{x})]\right]} \\
& {[[3]]=\lambda \mathrm{Z}_{\mathrm{i}} \cdot \forall \mathrm{z}\left[\mathrm{z} \in \mathrm{Z}_{\mathrm{iCov}} \rightarrow \exists \mathrm{x}[\text { really }(\mathrm{x}) \& \text { scratches }(\mathrm{z}, \mathrm{x})]\right]} \\
& {[[4]]=\forall \mathrm{z}\left[\mathrm{z} \in \text { token }[[\text { this pen }]]_{\text {Cov }} \rightarrow \exists \mathrm{x}[\text { really }(\mathrm{x}) \& \text { scratches }(\mathrm{z}, \mathrm{x})]\right]}
\end{aligned}
$$

\section{Commonality of the Adorning Materials}

In the above, we examined Joh's (2016) analysis of middle constructions which considers adverbs as one of the core arguments. However, even when there is no overt adverb, the middle construction can be licensed if and only if an implicit adverbial argument with the sense of unexpectedness can be inserted.

Now, we can turn back to the very issue of this paper: The adorning materials in middle constructions in (2) commonly reveal that they all can be transformed into adverbials. In this section, we will discuss modal adverbs, focusing adverbs and negative adverbs, one by one, to show that modality, focus and negation all can be expressed by alternative adverbials.

\subsection{Modal adverbs}

As largely known, modality can be expressed by adverbs. Suzuki and Fuijiwara (2017) nicely summarizes the classifications of modal adverbs. In the following, we will introduce them. First, Greenbaum (1969:203) puts forth the classification of modal adverbs as in (16).

(16) a. Those that express conviction: admittedly, assuredly, certainly, decidedly, definitely, incontestably, indeed, indisputably, indubitably, surely, unarguably, undeniably, undoubtedly, unquestionably

b. Those that express some degree of doubt: allegedly, arguably, conceivably, doubtless, quite likely, maybe, perhaps, possibly, presumably, probably, reportedly, reputedly, supposedly

Hoye (1997: 1884) provides a similar classification of modal adverbs as in (17). Since there are two groups in this classification just like the Greenbaum's 
classification, this classification is not much novel but some adverbs are deleted or added.

(17) a. Content disjuncts expression conviction: admittedly, certainly, definitely, indeed, surely, undoubtedly, clearly, evidently, obviously, of course, plainly

b. Content disjuncts expressing doubt: arguably, apparently, conceivably, doubtless, (quite/very) likely (informal), maybe (informal), perhaps, possibly, presumably, probably

Yet, Huddleston and Pullum (2002: 768) advances an alternative classification of modal adverbs as in (18). In their classification, modal adverbs are classified into four groups in terms of their strength.

(18) a. Strong: assuredly, certainly, clearly, definitely, incontestably, indubitably, ineluctably, inescapably, manifestly, necessarily, obviously, patently, plainly, surely, truly, unarguably, unavoidably, undeniably, undoubtedly, unquestionably

b. Quasi-strong: apparently, doubtlessly, evidently, presumably, seemingly

c. Medium: arguably, likely, probably

d. Weak: conceivably, maybe, perhaps, possibly

As discussed above, modality can be expressed by adverbials of various types. Depending on different researchers, they might be classified a bit differently. However, it is hard to deny that modality can be conveyed by means of adverbials.

\subsection{Focusing adverbs}

Focus can also be expressed by adverbials. There are various types of focusing adverbs. Abbas (2013) lists some types of focusing adverbs as follows.

(19) a. additive adverbs: also, neither, as well, both, too, in addition, either, yet, even

b. particularizer adverbs: chiefly, particularly, at least, especially

c. exclusive adverbs: precisely, exactly, purely, just, simply, merely

d. intensifiers: almost, badly, barely, completely, considerably, deeply, enough, entirely, less/least, much/more/most, nearly, quite, rather, slightly, somewhat, strongly 


\subsection{Negative adverbs}

The online syntax textbook used in University of Pennsylvania also discusses the negative adverb never. It is shown that there is a syntactic difference between the negative particle not and the negative adverbial never, as illustrated below.

a. $\mathrm{NegP}$

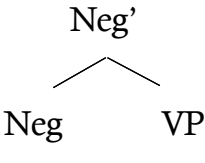

not b. $\operatorname{AdvP}$

Adv'

Adv

never

The syntactic difference is claimed to make the following grammatical contrast. Thus, there is a negative adverbial never which can be fronted or moved, in addition to various adverbials that denote negativity such as hardly, scarcely, etc.

(21) a. Never will they tolerate this mess.

b. ${ }^{*}$ Not will they tolerate this mess.

As discussed in this section, it seems to be an interesting fact that negation can also be expressed by adverbials.

\section{Analysis of the Middles with Adorning Materials}

In the previous section, we have shown that the common property of modals, focus and negation is that they all can be expressed by adverbials. Considering the claim that the adverbial is one of the core arguments of middle constructions, this common adverbial property of the adorning materials does not seem coincidental. Thus, this paper would like to claim that the middle sentences in (2) can be licensed since the adorning materials are translated into adverbials which can serve as the DstrShr of distributivity. The analysis for this claim will be provided in the following. 


\subsection{Middles with modal verbs}

To analyze middle sentences with adorning materials, we can use the same pluralization operator and Bittner's (1994) lambda-abstraction rule that Joh (2016) employed. Yet, to address the shifted order between the modal, negation, focus and the modal adverbial, negative adverbial, focusing adverbial, respectively, we will slightly revise the pluralization operator. In Joh (2016), the first argument of the pluralization operator is fixed as the DstrShr. Yet, equipped with Bittner's lamda-abstraction rule, this is not a necessary part. Thus, we will make it more flexible and make it possible to apply to the Relation first, and then to the DstrShr and the SrtKy. This change can be simply implemented by defining the pluralization operator as below. The pluralization operator in (22) can make the order of all the arguments free, as Joh (2014) discusses. Then, through Bittner's lambda-abstraction rule, the variable for the right argument can be lambda-abstracted when the operator meets the argument syntactically.

$$
\text { (22) } \forall \mathrm{z}_{<\alpha>}\left[\mathrm{z} \in \mathrm{Z}_{\mathrm{i}<\alpha, \mathrm{t}>\operatorname{Cov}} \rightarrow \exists \mathrm{x}_{<\alpha>}\left[\mathrm{P}_{\mathrm{k}<\alpha, \mathrm{t}>}(\mathrm{x}) \& \mathrm{R}_{\mathrm{j}<\mathrm{e},<\alpha, \mathrm{t}>>}(\mathrm{x})(\mathrm{z})\right]\right]
$$

First, let us look at how we can handle the middle sentence with the adorning material, a modal verb. In this case, the modal verb could in (23a) can be translated into the matching modal adverbial possibly as in (23b) which can serve as the DstrShr. Now, this sentence is composed of three essential arguments of distributivity. Thus, the pluralization operator can be evoked and generate the sense that each of the hand-made clothes possibly sell. Yet, since the plural subject comes with the Cover variable, the maximality of the subject can naturally be adjusted allowing for exceptions.

(23) a. The hand-made clothes could sell.

b. The hand-made clothes probably sell. 
(24)

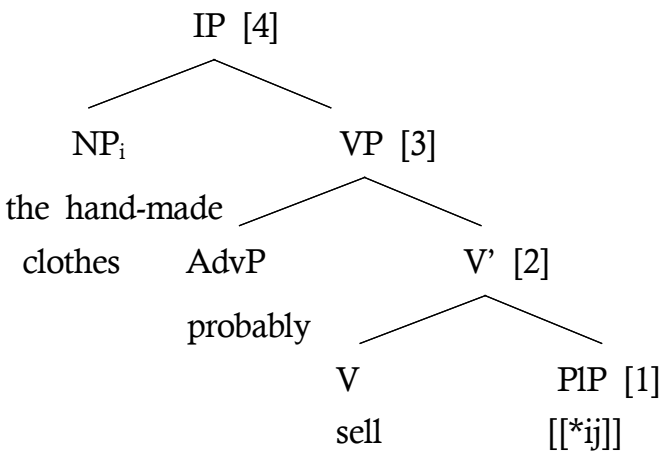

$[[1]]=\forall z\left[z \in Z_{\text {iCov }} \rightarrow \exists x\left[P_{\mathrm{k}}(\mathrm{x}) \& \mathrm{R}_{\mathrm{j}}(\mathrm{x})(\mathrm{z})\right]\right]$

$[[2]]=\lambda R_{\mathrm{j}} \cdot \forall \mathrm{z}\left[\mathrm{z} \in \mathrm{Z}_{\mathrm{iCov}} \rightarrow \exists \mathrm{x}\left[\mathrm{P}_{\mathrm{k}}(\mathrm{x}) \& \mathrm{R}_{\mathrm{j}}(\mathrm{x})(\mathrm{z})\right]\right]$

$[[2]]=\forall z\left[z \in Z_{\text {iCov }} \rightarrow \exists x\left[P_{\mathrm{k}}(\mathrm{x}) \&\right.\right.$ sell $\left.\left.(\mathrm{z}, \mathrm{x})\right]\right]$

$[[3]]=\lambda P_{\mathrm{k}} \cdot \forall \mathrm{z}\left[\mathrm{z} \in \mathrm{Z}_{\mathrm{iCov}} \rightarrow \exists \mathrm{x}\left[\mathrm{P}_{\mathrm{k}}(\mathrm{x}) \&\right.\right.$ sell $\left.\left.(\mathrm{z}, \mathrm{x})\right]\right]$

$[[3]]=\forall z\left[z \in Z_{\text {iCov }} \rightarrow \exists x[\right.$ probably $(x) \&$ sell $\left.(\mathrm{z}, \mathrm{x})]\right]$

$[[4]]=\lambda Z_{i} \cdot \forall z\left[z \in Z_{\text {iCov }} \rightarrow \exists x[\right.$ probably $(x) \&$ sell $\left.(\mathrm{z}, \mathrm{x})]\right]$

$[[4]]=\forall \mathrm{z}\left[\mathrm{z} \in[[\text { the hand-made clothes }]]_{\mathrm{Cov}} \rightarrow \exists \mathrm{x}[\right.$ probably $(\mathrm{x}) \&$ sell $\left.(\mathrm{z}, \mathrm{x})]\right]$

\subsection{Middles with negation}

Next, the middle sentence with the negative particle not shown in (25a) can be translated into the sentence with the negative adverbial never as in (25b). Then, the pluralization operator that has three variables for the SrtyKy, the DstrShr and the Relation are lambda-abstracted one by one to be filled with the right value. The order can be flexible under Bittner's lambda-abstraction rule. Thus, as above, the pluralization operator first applies to the Relation, then to the DstrShr and finally to the SrtKy. The final semantic outcome of the derivation is that each of this paper never cuts, where the universal quantificational force can be contextually adjusted by being equipped with the Cover variable.

(25) a. This paper does not cut.

b. This paper never cuts. 
(26)

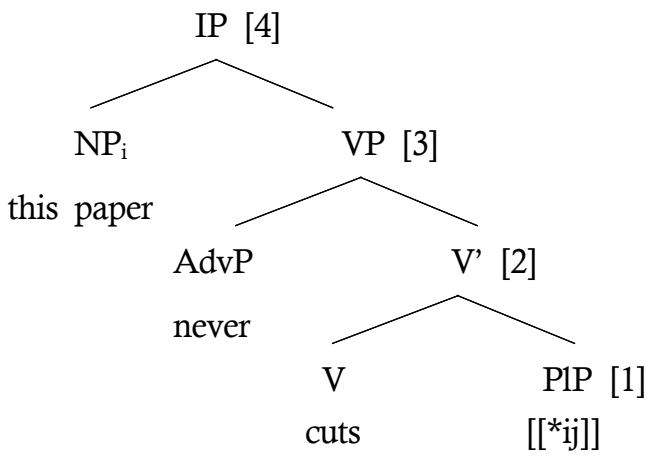

$$
\begin{aligned}
& {[[1]]=\forall \mathrm{z}\left[\mathrm{z} \in \mathrm{Z}_{\mathrm{iCov}} \rightarrow \exists \mathrm{x}\left[\mathrm{P}_{\mathrm{k}}(\mathrm{x}) \& \mathrm{R}_{\mathrm{j}}(\mathrm{x})(\mathrm{z})\right]\right]} \\
& {[[2]]=\lambda \mathrm{R}_{\mathrm{j}} \cdot \forall \mathrm{z}\left[\mathrm{z} \in \mathrm{Z}_{\mathrm{iCov}} \rightarrow \exists \mathrm{x}\left[\mathrm{P}_{\mathrm{k}}(\mathrm{x}) \& \mathrm{R}_{\mathrm{j}}(\mathrm{x})(\mathrm{z})\right]\right]} \\
& {[[2]]=\forall \mathrm{z}\left[\mathrm{z} \in \mathrm{Z}_{\mathrm{iCov}} \rightarrow \exists \mathrm{x}\left[\mathrm{P}_{\mathrm{k}}(\mathrm{x}) \& \text { cuts }(\mathrm{z}, \mathrm{x})\right]\right]} \\
& {[[3]]=\lambda \mathrm{P}_{\mathrm{k}} \cdot \forall \mathrm{z}\left[\mathrm{z} \in \mathrm{Z}_{\mathrm{iCov}} \rightarrow \exists \mathrm{x}\left[\mathrm{P}_{\mathrm{k}}(\mathrm{x}) \& \text { cuts }(\mathrm{z}, \mathrm{x})\right]\right]} \\
& {[[3]]=\forall \mathrm{z}\left[\mathrm{z} \in \mathrm{Z}_{\mathrm{iCov}} \rightarrow \exists \mathrm{x}[\text { never }(\mathrm{x}) \& \text { cuts }(\mathrm{z}, \mathrm{x})]\right]} \\
& {[[4]]=\lambda \mathrm{Z}_{\mathrm{i}} \cdot \forall \mathrm{z}\left[\mathrm{z} \in \mathrm{Z}_{\mathrm{iCov}} \rightarrow \exists \mathrm{x}[\operatorname{never}(\mathrm{x}) \& \text { cuts }(\mathrm{z}, \mathrm{x})]\right]} \\
& {[[4]]=\forall \mathrm{z}[\mathrm{z} \in \text { token }[[\text { this paper] }] \text { Cov } \rightarrow \exists \mathrm{x}[\operatorname{never}(\mathrm{x}) \& \text { cuts }(\mathrm{z}, \mathrm{x})]]}
\end{aligned}
$$

\subsection{Middles with focus}

A similar analysis can be provided for the sentence with focus. The accentual focus placed on the predicate buttons can be translated into a focusing adverbial particularly as shown in (27b). Then the same mechanism can generate the semantics of the middle sentence: 'each of this dress particularly buttons' under the condition that the maximality involved with the distributivity can be reduced with some exceptions allowed by the contextual Cover variable.

(27) a. This dress BUTTONS.

b. This dress particularly buttons. 
(28)

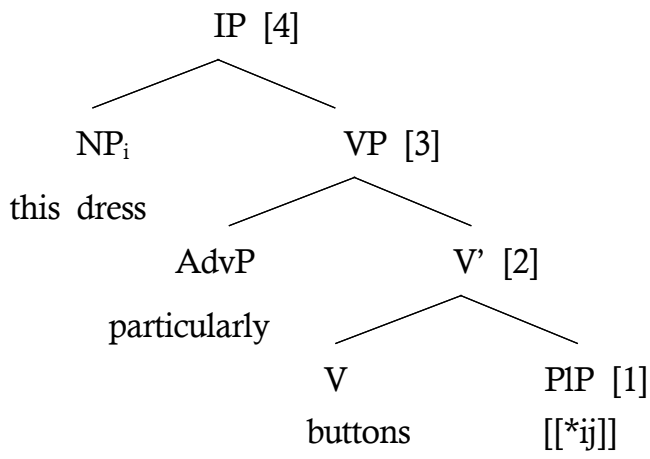

$$
\begin{aligned}
& {[[1]]=\forall z\left[z \in Z_{\text {iCov }} \rightarrow \exists x\left[P_{k}(x) \& R_{j}(x)(z)\right]\right]} \\
& {[[2]]=\lambda R_{\mathrm{j}} \cdot \forall \mathrm{z}\left[\mathrm{z} \in \mathrm{Z}_{\mathrm{iCov}} \rightarrow \exists \mathrm{x}\left[\mathrm{P}_{\mathrm{k}}(\mathrm{x}) \& \mathrm{R}_{\mathrm{j}}(\mathrm{x})(\mathrm{z})\right]\right]} \\
& {[[2]]=\forall z\left[z \in Z_{\text {iCov }} \rightarrow \exists x\left[P_{k}(x) \& \text { buttons }(z, x)\right]\right]} \\
& {[[3]]=\lambda P_{k} \cdot \forall z\left[z \in Z_{\text {iCov }} \rightarrow \exists x\left[P_{k}(x) \& \text { buttons }(z, x)\right]\right]} \\
& {[[3]]=\forall z\left[z \in Z_{\text {iCov }} \rightarrow \exists x[\text { particularly }(x) \& \text { buttons }(\mathrm{z}, \mathrm{x})]\right]} \\
& {[[4]]=\lambda Z_{i} \cdot \forall z\left[z \in Z_{\text {iCov }} \rightarrow \exists x[\text { particularly }(x) \& \text { buttons }(z, x)]\right]} \\
& \left.[[4]]=\forall z[z \in \text { token [[this dress] }]_{\text {Cov }} \rightarrow \exists x[\text { particularly }(\mathrm{x}) \& \text { buttons }(\mathrm{z}, \mathrm{x})]\right]
\end{aligned}
$$

\section{Discussion}

In the section above, we have translated a modal verb, negation and focus into the adverbials like possibly, never, and particularly. Then, the question is whether there is any condition for the adverbials. Joh (2016) talks about the unexpectedness effect relying on the observation made by Cho (2002). When there is no overt adverbial in the middle sentence, an implicit adverbial can be inserted. This is why some middles can survive even without an overt adverbial. Yet, this is not always possible but is strictly conditioned since the following sentences in (29) cannot be considered acceptable. In the sentences in (29), it is generally expected that all the books are read and all the chickens are killed since it is ordinarily perceived that books are for reading and chickens are raised for foods. Thus, Joh (2016) claims that an implicit adverbial can be inserted only when it can contribute the meaning of unexpectedness.

(29) a. *Books read.

b. ${ }^{*}$ Chickens kill. 
This raises the question whether the replacing adverbials like possibly, never and particularly in this paper can also meet the unexpectedness condition. They are translations of the overt part of the middle sentences. However, they are also implicitly inserted to serve as one of the core arguments. Yet, it seems that the replacing adverbials are a bit different from the adverbials expressing unexpectedness like really. Then, how can we generalize the condition for inserting adverbials in middle sentences? To discuss this issue, I would like to examine the differentiating effect of Sohn (2002, 2003) who cites previous studies like Dowty (2001) and Fellbaum (1986).

Sohn (2003) accounts for the semantics of middle sentences as in (30). In the account, she claims that the CHARACTERIZING property of middle sentences can be understood as the differentiating effect.

(30) In middle sentences, the predicate phrase has the effect of CHARACTERIZING the INHERENT PROPERTY of the subject, with respect to the performative feasibility, degree or manner of the event the verb denotes.

She finds the origin of her claim in Dowty (2001) who characterizes middle sentences as in (31). According to Dowty (2001), the object of middle sentences is compared to other objects. Sohn (2003) claims that this intrinsic comparison character can result in the differentiating effect of middle sentences as well.

(31) The Middle Verb Construction compares one object (implicitly) to other objects indirectly: via comparing the ACTION performed on the first object, to the same action performed on the other objects; the actions are compared with respect of ease, difficulty, time needed, etc. in performing them.

According to Sohn (2003), Fellbaum (1986) also talks about the similar effect of middle sentences. In the following middle sentences, the implied meaning is that not all umbrellas can be folding but only each token of the particular umbrella is folding. Thus, when the sentence talks about a particular umbrella, the sentence is differentiating the particular object from other objects of the same type.

(32) This umbrella folds up in the pocket.

Citing Fellbaum (1986), Sohn (2003) also discusses that the differentiating effect 
might be responsible for the fact that middle constructions are highly useful in advertisements as follows.

(33) a. The DT2871 connects directly to DT.

(used in data translation to connect processor boards for faster computer)

b. The Velcro fastener locks on contact.

(the nuts and bolts of a better-built car)

c. [Our new CleanTop range brings smooth-topcooking and cleaning performance to a new level.] The elements heat up in a remarkable ten seconds.

Now, the discussion of this section is to compare the unexpectedness effect that Joh (2016) discusses based on Cho (2002) with the differentiating effect that Sohn (2003) examines. To explain the insertion of an implicit adverbial in middles, which one might be more appropriate? Of course, the adverbials that replace the adorning materials in middles are not out of nowhere but the translations of the very parts of the middle sentences. Yet, the adverbials are also inserted implicitly. Thus, the question is whether there are any common aspects of the replacing adverbials and implicit adverbials in general.

It seems that the modal adverbial probably, the negative adverbial never and the focusing adverbial particularly all have the effect of differentiating the object in the middle sentences from other objects that do not have the same property. When the modal adverbial possibly is inserted, it is differentiated from the objects which are not possible. When the negative adverbial never is inserted, it is also differentiated from the objects which can be affirmative. The focusing adverbial does a similar function. When the adverbial particularly is inserted, the object in the middle sentence is differentiated from other objects which are not in particular. Thus, we might describe the common effect of the adverbials that replacing modality, negation and focus as the differentiating effect.

Then, the next question is whether this differentiating effect is totally different from the unexpectedness sense that Cho (2002) argues for. I believe not. The differentiating effect that has been observed by various previous studies seems to encompass the unexpectedness sense that Cho (2002) recognizes since something different can include the cases that are unexpected. Thus, the condition for inserting implicit adverbials in middles can more generally be extended from the unexpectedness sense to the differentiating effect. Thus, the default implicit adverbial 
does not have to be confined to adverbials like really but can be extended to more general differentiating adverbials.

One might doubt whether the differentiating effect is one of the inherent properties of middle sentences. In fact, not all middles reveal the effect of differentiating. Sohn (2003) provides the following counter-examples. Yet, the commonality of the following counter-examples is that they all are already filled with an overt adverbial. There seem to be few middle sentences that do not reveal the differentiating effect if they do not come with an overt adverbial. Thus, we might conjecture that the differentiating effect can condition the insertion of implicit adverbials in middles even though all the overt adverbials in middles do not have to show the effect.

(34) a. Oil separates from water easily.

b. Glass breaks easily.

c. Any bureaucrat bribes easily.

\section{Conclusion}

This paper has tried to solve the puzzle raised by Chung (2001). Some adorning materials in middles such as modality, negation and focus make the construction better acceptable. Previously, the common properties of these adorning materials remained to be answered. This paper has claimed that the very common property of the adorning materials is they all can be translated into adverbials. This property can be viewed more interesting under the analysis that views middle constructions as distributivity constructions where the adverbial serves as one of the core arguments. Thus, this paper has provided accounts for the adorning materials in middles under the analysis Joh (2016) previously advanced who treats adverbials as arguments. Then, this paper has further discussed that the condition for implicitly inserted adverbials in middles can be characterized as the differentiating effect that Sohn (2003) discusses, being extended from the unexpectedness sense, since all the adverbials that replace adorning materials in middles are also considered as adverbials which are implicitly inserted. 


\section{References}

Abbas, A. (2013). Focusing adverbs in medical academic discourse. Adab al-Kufa 6(16), 37-56.

Bittner, M. (1994). Cross-linguistic semantics. Linguistics and Philosophy 17, 53-108.

Cho, M-C. (2002). A semantic approach to English middle construction. Master's thesis. Chosun University.

Choe, J-W. (1987). Anti-quantifiers and a theory of distributivity. Ph.D. dissertation. University of Massachusetts.

Chung, T. (2001). Implicit arguments in English middles. Korea Journal of English Language and Linguistics 1(2), 331-347.

Dowty, D. (2001). The Semantic Asymmetry of Argument Alternations; (and why it matters.) unpublished manuscript. <http://ling-ohio-state.edu/ dowty>

Fellbaum, C. (1986). On the middle construction in English. Bloomington: Indiana University Linguistics Club.

Greenbaum, S. (1969). Studies in English adverbial usage. Coral Gables: University of Miami Press.

Hoye, L. (1997). Adverbs and modality in English. London: Longman.

Huddleston, R. \& Pullum, G. (2002). The Cambridge Grammar of the English Language. Cambridge: Cambridge University Press.

Joh, Y-K. (2014). English each and Korean kakkak. The Journal of Modern British \& American Language \& Literature 32(2), 31-50.

Joh, Y-K. (2016). Middle constructions and distributivity. Language Research 52(3), 557-577.

Krifka, M., Pelletier, J., Carlson, G., ter Meulen, A., Link, L., \& Chierchia, G. (1995). Genericity: An Introduction. In G. Carlson \& F. Pelletier, (eds.), The generic book (pp. 1-124). Chicago: The University of Chicago Press.

Landman, F. (2000). Events and plurality: The Jerusalem lectures. Dordrecht: Kluwer.

Lee, M-O. (2001). Recursiveness condition in the English middle construction. Korean Journal of Linguistics 26, 735-754.

Roberts, I. (1987). The representation of implicit and dethematized subjects. Dordrecht: Foris.

Sohn, Y-M. (2002). Interpretation of English middle constructions. The History of English 14, 1-19.

Sohn, Y-M. (2003). Middle constructions in English: The syntax-lexical semantics interface. Doctoral dissertation. Seoul National University.

Suzuki, D. \& Fujiwara, T. (2017). The multifunctionality of 'possible' modal adverbs: A comparative look. Language 93(4), 827-841.

Zimmermann, M. (2002). Two sausages each: On the syntax and semantics of distance-distributivity. Doctoral dissertation. University of Amsterdam. 
Yoon-kyoung Joh

Associate Professor

English Language and Literature Department

Mokpo National University

1666 Yeongsan-ro, Cheongye-myeon, Muan 58554, Korea

E-mail: ykjoh@mokpo.ac.kr

Received: February 10, 2020

Revised version received: March 14, 2020

Accepted: March 29, 2020 